\title{
OCCURRENCE OF TROGLOBITIC CLIVININES IN CHINA (INSECTA: COLEOPTERA: CARABIDAE)
}

\author{
Mingyi Tian \\ Department of Entomology, College of Natural Resources and Environment, South China Agricultural University, Wushanlu 483, Guangzhou, Guangdong, \\ 510640, China,mytian168@yahoo.com.cn
}

\begin{abstract}
A new genus, Guiodytes gen. nov., and two new species, G. cavicola sp. nov. and G. bedosae sp. nov., of the ground beetle tribe Clivinini (Coleoptera: Carabidae) are described from two caves of Guangxi, southern China. Guiodytes gen. nov. is characterized. It is the first genus of troglobitic clivinines discovered in Asia, and its relationships with other clivinines remain unclear.
\end{abstract}

\section{INTRODUCTION}

There are numerous cavernicolous carabid beetles recorded in the world (Casale et al., 1998). Many anophtalmous species belong to the tribe Clivinini of Scaritinae, especially to the humicolous genus Reicheia Saulcy, 1863. But there are a few eyeless troglobitic clivinine species: Italodytes stammeri Müller, 1938 (from Italy), Typhloreicheia monacha Casale and Marcia, 2011, and T. ilianae Casale and Marcia, 2011 (from Sardinia, Italy), Spelaeodytes mirabilis Miller, 1863 (from Croatia), Antroforceps bolivari Barr, 1967 (from Mexico), and Trogloclivina brehieri Deuve, 2003 (from New Britain Island, Papua New Guinea). Another troglobitic species, Clivina subterranea Decu, Nitzu and Juberthie, 1994 (from Romania), is not blind.

In China, the first highly modified troglobitic carabid species, Sinaphaenops mirabilissimus Ueno and Wang, was described in 1991 (Ueno and Wang, 1991). All Chinese troglobitic ground beetles are members of either the tribe Trechini or the tribe Platynini. Trechini is the dominant group, represented so far by about eighty species of more than thirty genera (Chen et al., 2001; Tian, 2008). Although several species of the platynine genera Jujiroa Uéno, 1952 and Xestagonum Habu, 1978 have been recorded, all are microphthalmous, with reduced, but evident, eyes (Vigna Taglianti, 1995; Ueno and Kishimoto, 2001; Deuve, 2001, 2004; Ueno, 2007).

Recently, in collaboration with Dr. Louis Deharveng of the Muséum National d'Historie Naturelle in Paris, a biological survey on cave fauna was conducted in Guangxi, southern China, as part of research activities of the World Bank GEF-financed project Guangxi Integrated Forestry Development and Conservation. One of the most important discoveries during the survey was that of two interesting specimens of eyeless clivinines. This is the first record of blind carabid clivinines in China. Detailed study showed that they correspond to two different species of a new genus.

\section{Materials And Methods}

The specimens were collected by hand in caves of Guangxi and preserved in $60 \%$ ethanol solution before study. Other surface or soil species of clivinines, dry and mounted specimens, were examined for comparison. All specimens are deposited in the insect collections of South China Agricultural University, Guangzhou, Guangdong Province.

Dissection and observation were conducted under a Leica S8AP0 microscope. Genitalia and related pieces of small structures were removed, put in $10 \%$ potassium hydroxide for 24 hours for cleaning, then stuck on paperboard and pinned beneath the associated specimen. Pictures were taken by means of a Leica Microsystem LAS V 3.6, and then processed using Adobe Photoshop CS5 software.

Abbreviations used in the text are as the same as described in Tian (2009): $\mathrm{HW}=$ head width; $\mathrm{HL}=$ head length; $\mathrm{PW}=$ pronotal width; $\mathrm{PL}=$ pronotal length; $\mathrm{EW}=$ elytral width; EL=elytral length. The terms for female genitalia are as in Deuve (1993).

\section{RESUlts}

GUIODYTES, GEN. NOV.

Type species: Guiodytes cavicola sp. nov. (Guangxi)

Generic characteristics: Description is based entirely on females. Habitus as in Figures 1 and 2. Body moderately elongate; upper side finely and sparsely punctate. Head stout, eyes effaced; wing of clypeus narrow, sharply projected anteriorly; both supraorbital setiferous pores present, located far from each other; supraorbital furrows wide and long; supra-antennal plates well defined, broad and strongly convex, much wider than clypeal wings; frons and vertex convex; frons without carina or tubercle; orbits well developed, genae well developed; labrum complete, mandibles quite stout, left mandible without median tooth; maxillary palpi ensiform; neck constricted by punctures. Antennomeres 1 and 2 glabrous, with a longer preapical seta on antennomere 1 and a short one on base of antennomere 2; antennomere 2 normally jointed to antennomere 1; antenna pubescent from antennomere 3; antennomeres 5-10 cylindrical ( $G$. cavicola sp. nov.), or distinctly sub-moniliform (G. bedosae sp. nov.).

Pronotum (Figs. 8 and 9) peltate, median line not bifurcate anteriorly, with two normal setae at each side, 


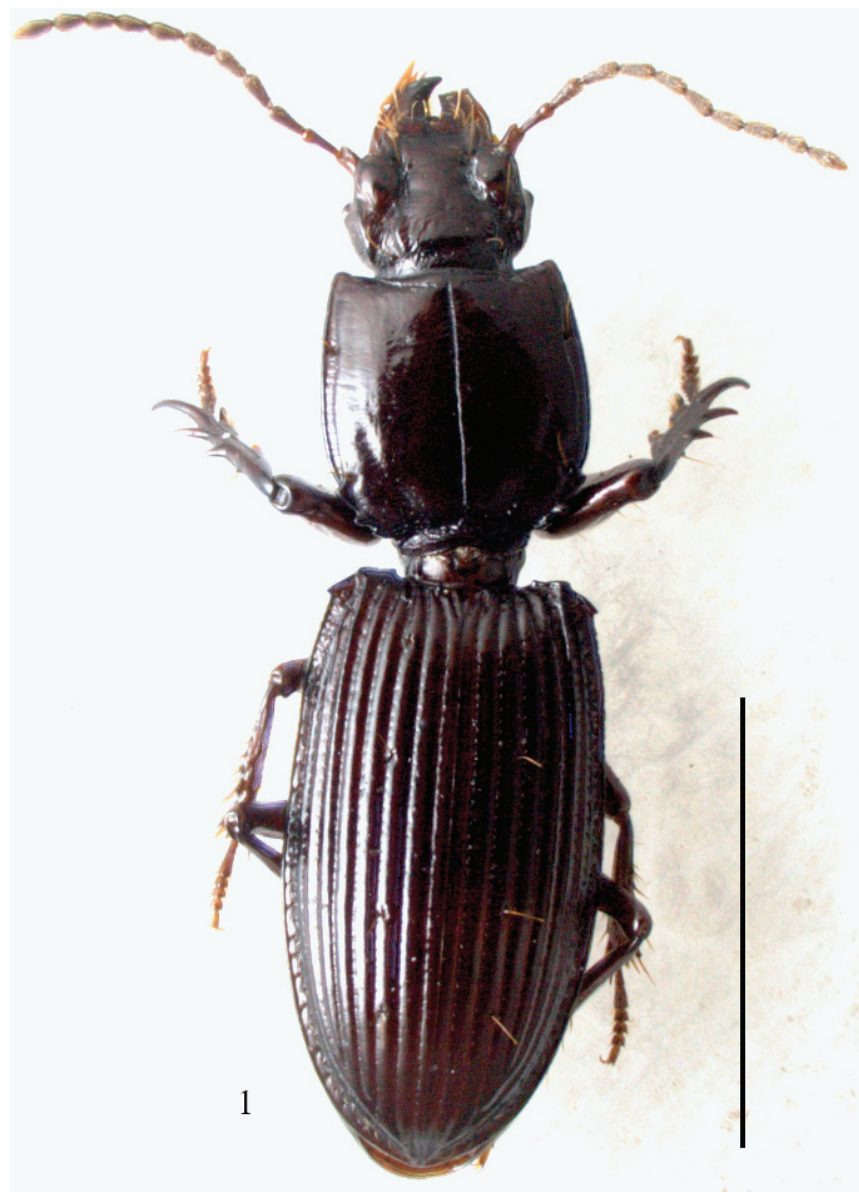

Figure 1. Guiodytes cavicola sp. nov., habitus of holotype.

one at anterior third, one near hind angle; median line well marked, moderately deep, not reaching base, but joining basal constriction; base of pronotum conspicuously depressed; side with three distinct teeth or projections before hind angle; hind angle nearly rectangular; basal border close to peduncle; anterior transverse impression free from median line, very close to anterior margin.

Elytra (Figs. 1 and 2) elongate-ovate, with base and shoulders serrate, lateral margin slightly undulate $(G$. cavicola sp. nov.) or distinctly crenulate ( $G$. bedosae sp. nov.); striae deep, intervals of subequal width, strongly convex; stria 3 with four foveolate setiferous pores; umbilical setiferous punctures complete throughout, with several much longer setae apart from the short ones; base of stria 6 evidently carinate, striae 7 and 8 jointed at base, carinate at base and apex respectively. Hind wings reduced.

Proepisternum not tumid laterally, invisible from above; protarsomere 1 not enlarged; mesotibia with a conspicuous tuber-like spur at subapex.

Female genitalia (Figs. 12 and 13): Both gonosubcoxite IX and gonocoxite IX strongly elongate, gonocoxite IX deeply ( $G$. cavicola sp. nov.) or slightly curved ( $G$. bedosae sp. nov.), sharp ( $G$. cavicola sp. nov.) or blunt ( $G$. bedosae sp. nov.) at apex, with ensiform setae on outer margin.

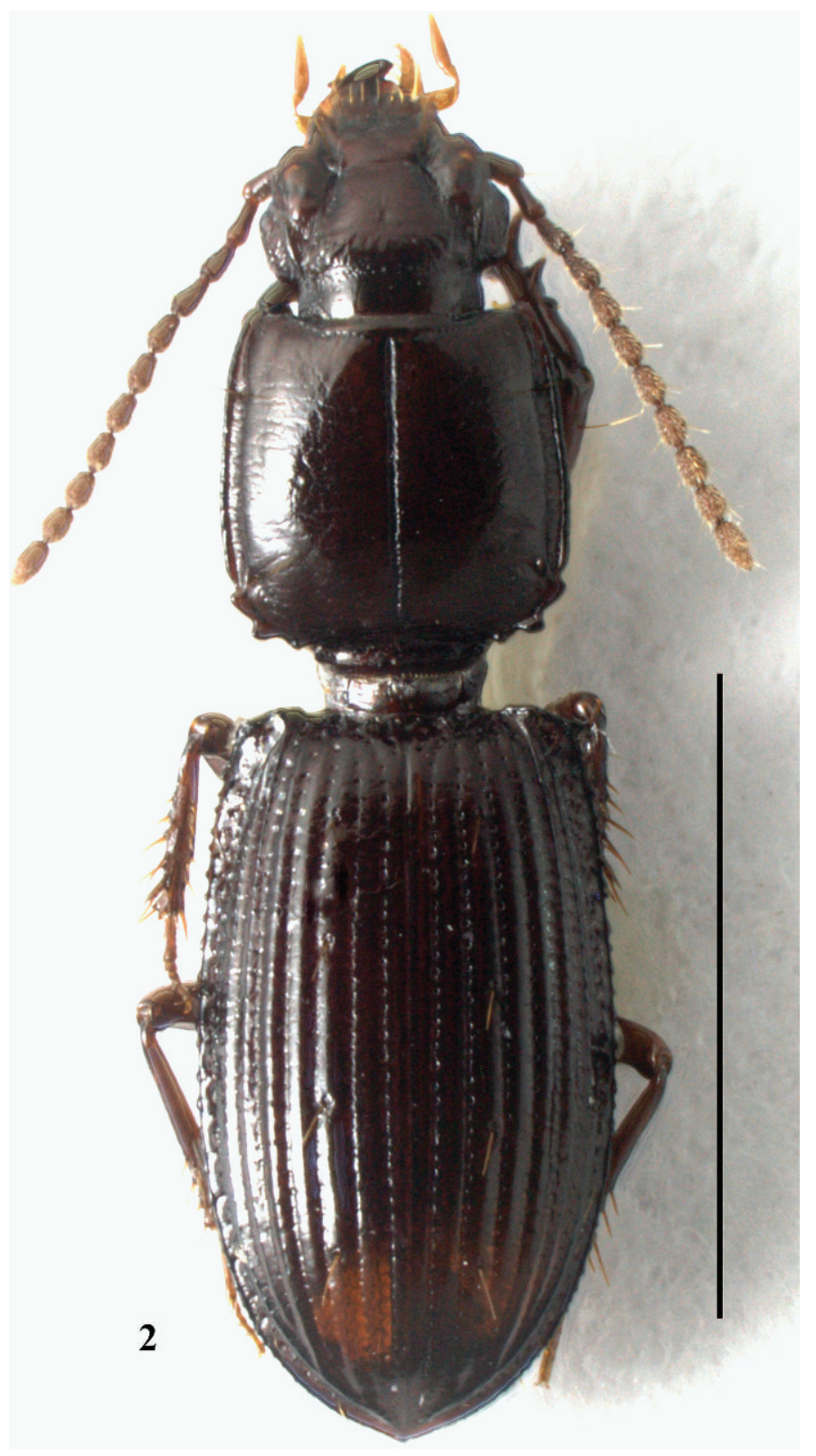

Figure 2. Guiodytes bedosae sp. nov., habitus of holotype.

Male: Unknown. In spite of our efforts, we were unable to catch another specimen in the caves, and no male is currently available. It is presumed that Guiodytes is as rare as many other cave dwelling species of Carabidae in China.

Relationship of Guiodytes within Clivinini: So far the known genera of anophthalmous clivinines are isolated. Italodytes Müller is endemic to Apulia, southern Italy, Spelaeodytes Miller, 1863 to Croatia, Antroforceps Barr, 1967 to Mexico, Trogloclivina to New Britain, Papua New Guinea, and Guiodytes to Guangxi, southern China. Jeannel (1957) was probably right to separate Italodytes from Clivinini, considering its peculiar morphological characteristics. Guiodytes is evidently closer to Trogloclivina than to Italodytes in appearance, but the relationships are not clear. In the absence of males, it is difficult to 


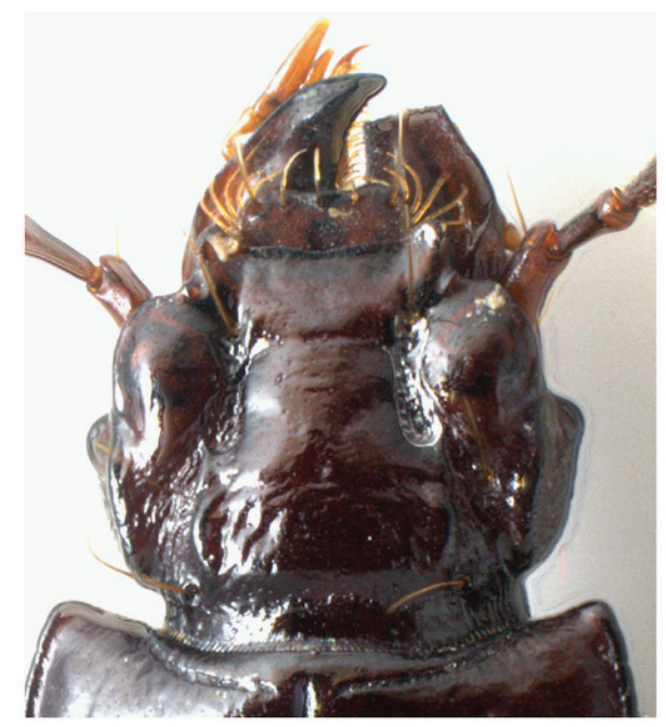

3

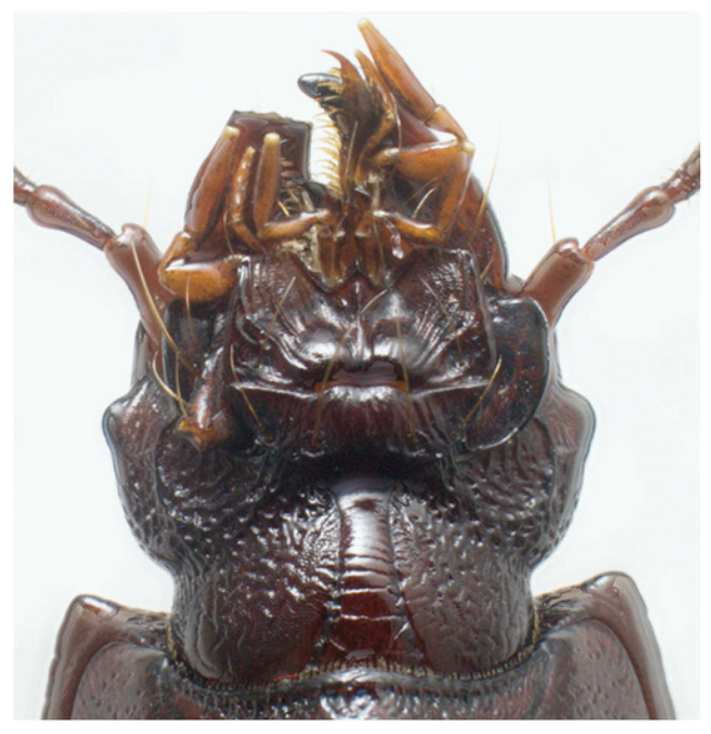

5

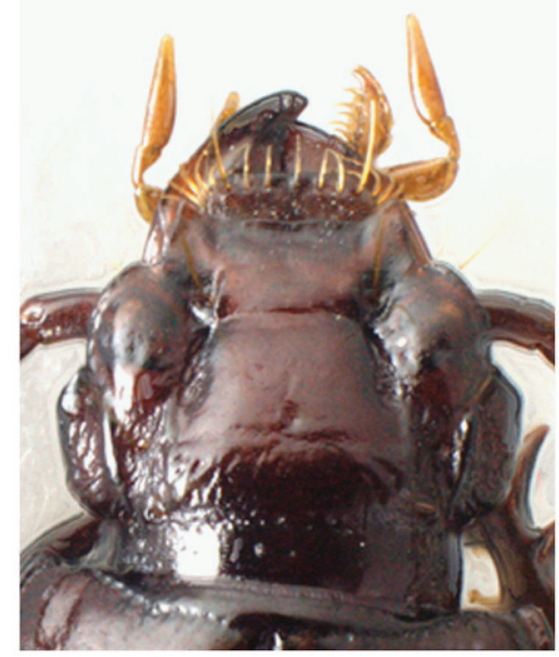

4

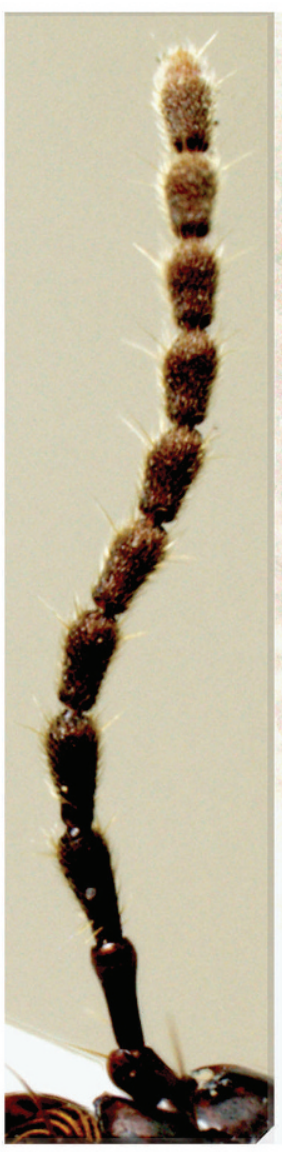

6

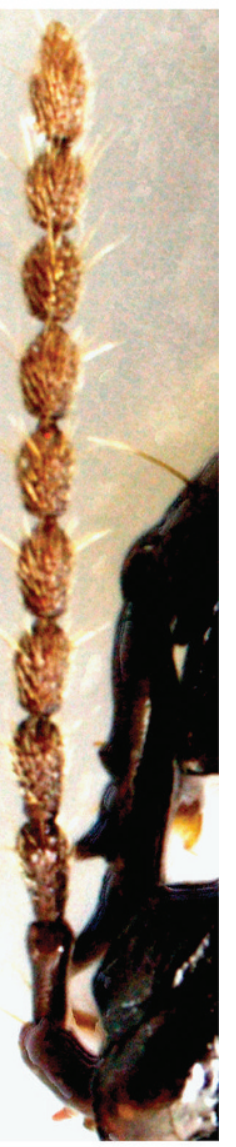

7

Figures 3-7. Guiodytes spp. nov.: 3. Head of G. cavicola, dorsal view. 4. Head of G. bedosae, dorsal view. 5. Head of G. cavicola, ventral view. 6. Right antenna of G. cavicola. 7. Right antenna of G. bedosae. 
discuss the phylogenetic position of Guiodytes within the Chinese or Oriental fauna of Clivinini (Putzeys, 1866; Baehr, 1999; Balkenohl, 1999, 2001; Yang and Tian, 2008). The new genus might have affinities with Clivina Latreille, 1802. It differs from Clivina by its eyes completely reduced, anterior and posterior supraorbital setiferous pores located far from each other, orbits and genae well developed, each of antennomeres 5-10 longer than wide, pronotum with three toothed projections just before hind angle, and hind wings reduced.

Adaptation of Guiodytes to subterranean environments: Apart from effaced eyes and reduced hind wings, no other evident morphological modifications were found in Guiodytes species for adapting to a subterranean environment. The appendages, such as palpi, antennae, and legs, are not more slender than those in surface species, though antennomeres 5-10 are more or less elongate. The body of Guiodytes is moderately elongate for Clivinini, and the elytral chaetotaxal pattern is not so special, as trichobothria are not very long. Although they look slightly lighter in color than surface or soil species of Clivinini, both species of Guiodytes are not depigmented.

Etymology: "Gui" is the abbreviation of Guangxi Zhuang Minority Autonomous Region in Chinese. The generic name, Guiodytes, refers to the distribution of the new genus.

Distribution: Southern China (Guangxi).

GUIODYTES CAVICOLA SP. NOV.

Holotype: Female, Nongshui Cave, Shangjia Cun, Disu Xiang, Du'an Xian, Hechi City, Guangxi, 23 $84.066^{\prime}$ N / $108^{\circ} 00.201^{\prime}$ E, 2010-IV-24, Mingyi Tian leg.

Description: Length (from apex of left mandible to end of elytra) $7.0 \mathrm{~mm}$; width $2.2 \mathrm{~mm}$.

Light dark brown; tarsi and antennae light brown, palpi yellow, apex of mandibles dark brown. Habitus as in Fig. 1.

Head (Figs. 3-5) stout, slightly longer than wide, HL/ $\mathrm{HW}=1.17$; narrower than pronotum $(\mathrm{HW} / \mathrm{PW}=0.71)$; clypeus wide, rather flat, bisetose, slightly emarginate at anterior margin; lateral wings narrow, projected anteriorly, extended distinctly beyond anterior margin of clypeus, separated from clypeus by an indistinct notch; supraantennal plates well defined, clearly separated from clypeal wings by obvious notch, more or less rounded, strongly convex, smooth and glabrous; frons and vertex convex; supraorbital furrows very deep and wide, extended to the level of hind supraorbital pore, subparallel along frons, strongly divergent afterwards; supraorbital carina absent; frons separated from clypeus by inconspicuous frontoclypeal suture; eyes completely reduced and disappeared; both anterior and posterior supraorbital pores present, located far from each other; genae well developed; neck constriction distinct, beginning at level of hind supraorbital pore; labrum conspicuously wide, as wide as clypeus excluding clypeal wings, 5-setose, and ciliate on both sides, almost straight at anterior margin; mandible stout, more or less widened, right mandible without median tooth; palpi ensiform, glabrous, apical segments of both maxillary and labial palpi much longer than penultimate ones respectively; labial palpomere 2 bisetose; ligula thin, unisetose at apex; mentum well developed, with two pairs of setae, one pair situated beneath mental tooth, other at base, close to side margins of mentum; median tooth pointed, lateral lobes wide, almost truncate at apex; submentum distinctly separated from mentum, quadrisetose. Antennae filiform (Fig. 6), comparatively long for Clivinini, extended to scutellum; antennomeres 1 and 2 glabrous and smooth, antenna pubescent from antennomere 3; antennomeres 2 and 3 subequal in length; antennomeres 5-10 subcylindrical, somewhat flat, distinctly longer than wide.

Pronotum (Fig. 8) peltate in form, much wider than head; disc smooth, moderately convex, slightly longer than wide (PL/PW = 1.09); apex deeply concave, marginated in median portion, anterior angles strongly protruded, nearly rectangular, widest at about middle; side strongly serrated just before hind angle, with three conspicuous toothed projections; marginal channel wide and uneven, widest near anterior lateral setiferous pore, ended before posterior lateral setiferous pore; anterior setiferous pore situated at about apical fourth, posterior one at about basal third, just before hind angle; base unbordered; median line clear and deep; basal transverse impression deep and wide, with several transverse striae behind and a small marginal denticle; anteror transverse line free from median line, very close to anterior margin. Peduncle distinct.

Elytra wider than pronotum $(\mathrm{EW} / \mathrm{PW}=1.10)$, elongate-ovate, $\mathrm{EL} / \mathrm{EW}=1.85$; disc strongly convex; lateral margin slightly expanded, widest at about middle; base more or less straight; shoulders broadly obtuse, with three large serrated teeth; lateral margin more or less smooth but undulate near base; striae deep, intervals strongly convex; interval 1 with a small but distinct tubercle at base, just before scutellar pore; intervals 5-9 bordered at base; intervals 6-8 carinate at base, base of intervals 7 and 8 joined; interval 3 with four setiferous pores, setae moderate in length for clivinines; marginal channel with uninterrupted series of small setiferous pores and several large pores with much longer setae; scutellar stria and scutellar pore present; hind wings reduced.

Underside of head and proepisternum with dense isodiametric punctures, without wrinkles; prosternum smooth, with sparse punctures; abdomenal sterna more or less punctured; sternum VII of female with two pairs of subapical setae; epipleuron with a few coarser punctures near base.

Legs not modified compared with surface clivinines; fore leg stout, profemur moderately dilated, smooth, without carina or ruga ventrally; protibia (Fig. 10) well developed, quadridentate, with distinct and complete carina dorsally, sulcus indistinct; lateral upper spine elongate-ensiform, blunt at apex, much longer and stouter than subapical spur; protarsi slender, tarsomere 1 very 

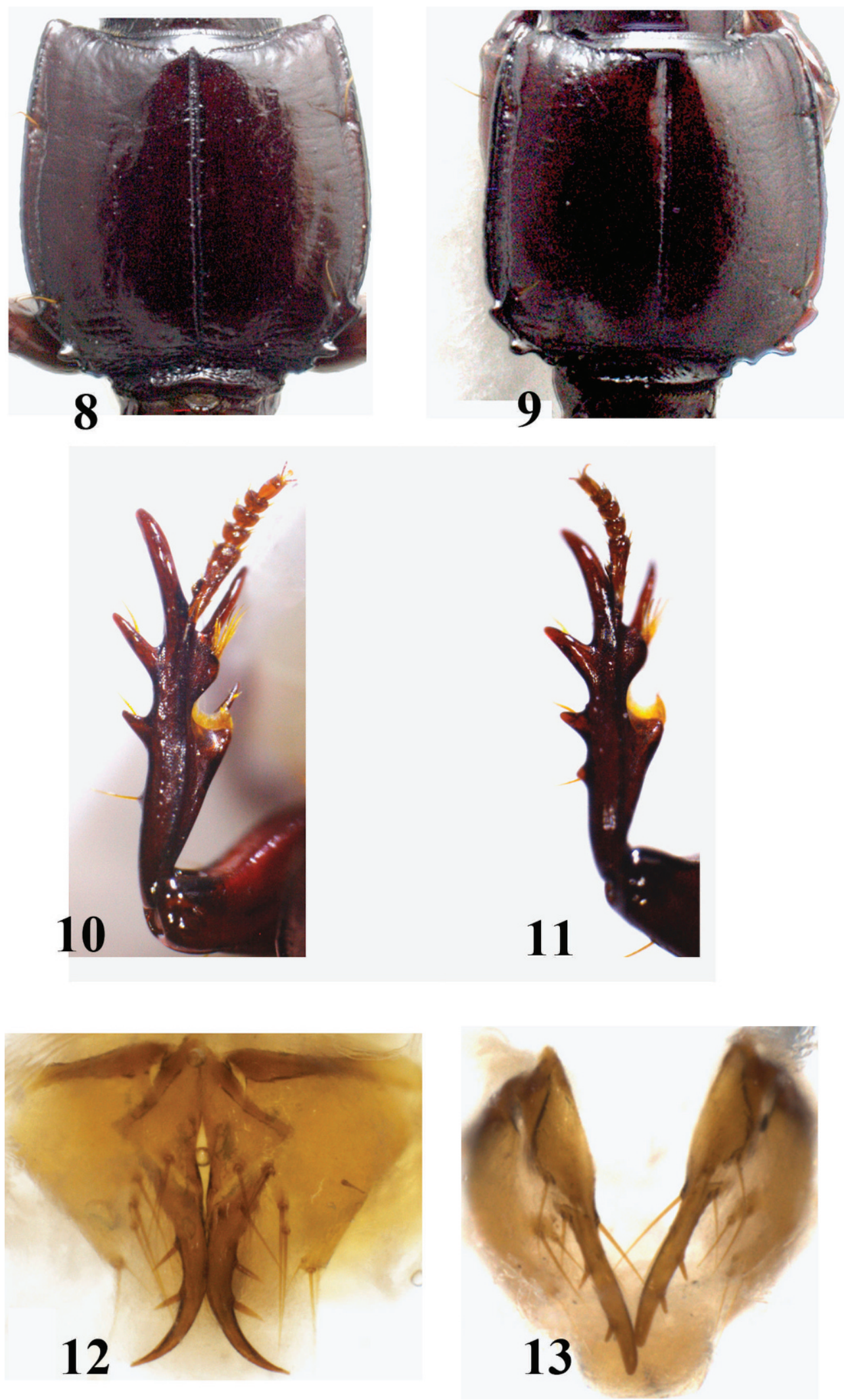

Figures 8-13. Guiodytes spp. nov.: 8. Pronotum of G. cavicola. 9. Pronotum of G. bedosae. 10. Protibia of G. cavicola, dorsal view. 11. Protibia of $G$. bedosae, dorsal view. 12. Female genitalia of $G$. cavicola, ventral view. 13. Female genitalia of $G$. bedosae, ventral view. 


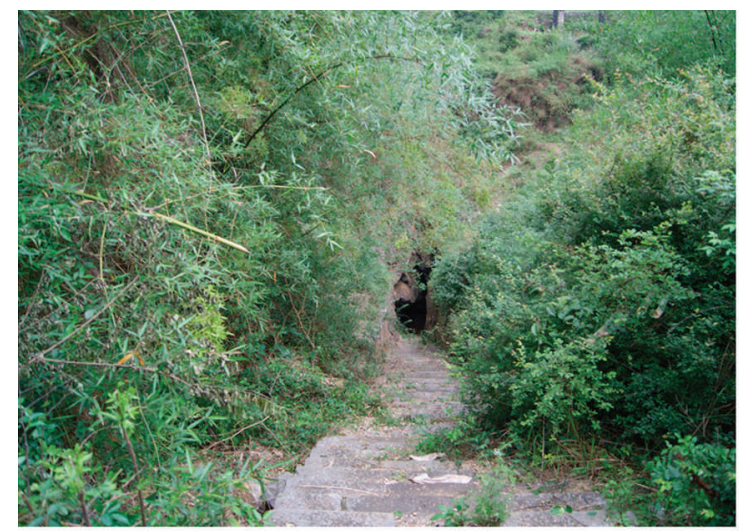

14

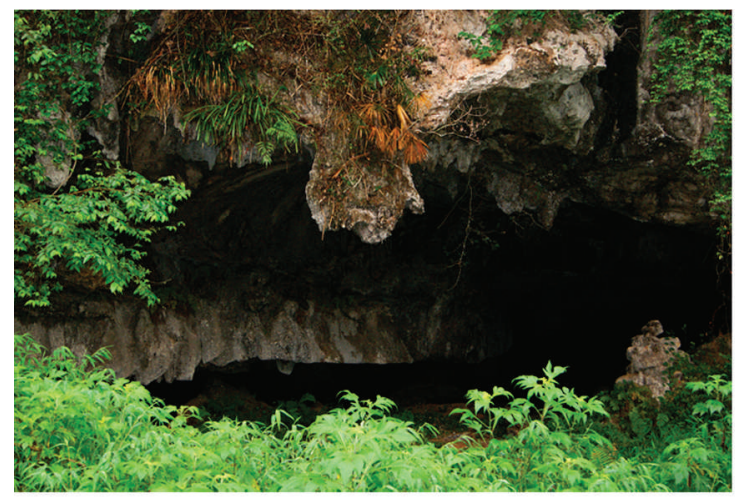

16

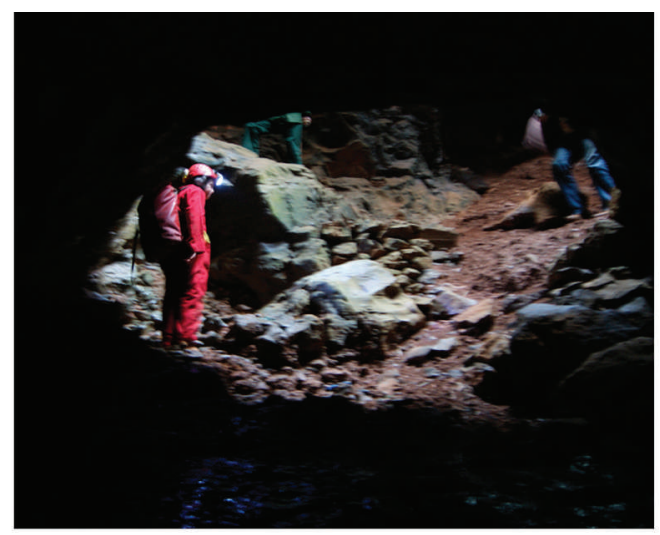

15

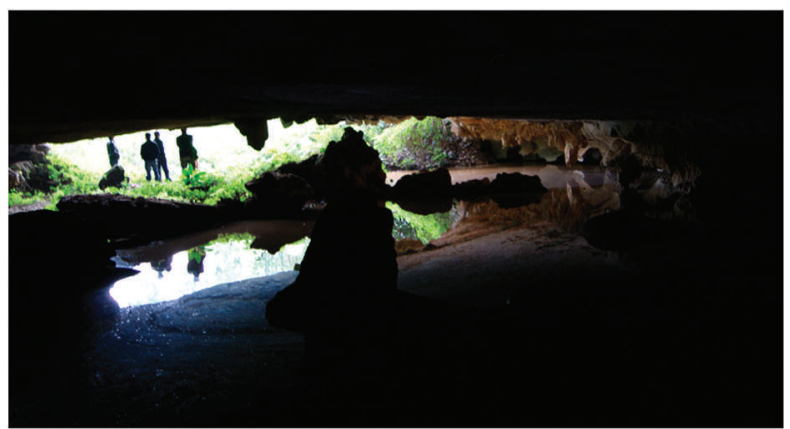

17

Figures 14-17. Habitat caves of Guiodyte: 14 and 15. Entrance of Nongshui Cave. 16 and 17. Entrance of Paoma Cave.

long, much longer than tarsomeres 2-4 combined; middle and hind legs slender, mesotibia gradually dilated towards apex, with a conspicuous tuber-like spur at subapex.

Female genitalia (Fig. 12): Lateralotergite IX well developed, nearly reverse triangular in form, with four long setae at subapex and apex; gonosubcoxite IX triangular, with one long seta at median portion of outer margin; gonocoxite IX very long and slender, gradually and evenly curved, very sharp at apex, with one long seta near base, and two strong and long ensiform setae on outer margin.

Male: Unknown.

Etymology: The name of this new species refers to its cave habitat.

Distribution: China (Guangxi: Du'an Xian). Known only from the type locality. It is a cave with torrential flooding just past the entrance (Figs. 14 and 15). Near the entrance there is a pumping station.

\section{GUIODYTES BEDOSAE SP. NOV.}

Holotype: Female, Paoma Cave, Xiadong Xiang, Longzhou Xian, Soutern Guangxi, 106 $86.903^{\prime}$ E / 22 $37.422^{\prime}$ N, 2010-IV-15, Mingyi Tian leg.
Description: Length (from apex of left mandible to end of elytra) $5.2 \mathrm{~mm}$; width $1.8 \mathrm{~mm}$.

Light dark brown; tarsi and antennae light brown, palpi yellow, apex of mandibles dark brown. Habitus as in Figure 2.

Head (Fig. 4) stout, slightly longer than wide, HL/LW $=1.20$, slightly narrower than pronotum $(\mathrm{HW} / \mathrm{PW}=$ 0.74); clypeus wide, rather flat, bisetose, distinctly emarginated at anterior margin; lateral wings narrow, projected anteriorly, extended clearly beyond anterior margin of clypeus, separated from clypeus by an indistinct notch; supra-antennal plate well defined, clearly separated from clypeal wing by an obvious notch, elongate-rounded, strongly convex, smooth and glabrous; frons and vertex convex; supraorbital furrow deep and wide, extended to level of hind supraorbital pore, slightly divergent along frons, posteriorly strongly divergent; supraorbital carina absent; frons separated from clypeus by inconspicuous frontoclypeal suture; eyes completely reduced; both anterior and posterior supraorbital pores present, located far from each other; genae well developed; neck broad, constriction distinct, beginning at level of hind supraorbital 
pore; labrum conspicuously wide, as wide as clypeus excluding clypeal wings, 7-setose, and ciliate on both sides, almost straight at anterior margin; mandible stout and widened, right mandible without median tooth; palpi ensiform, glabrous, stout, dilated at about basal third; apical segments of both maxillary and labial palpi much longer than penultimate ones respectively; labial palpomere 2 bisetose; ligula thin, unisetose at apex; mentum well developed, with two pairs of setae, one pair situated beneath mental tooth, other at base close to side margins of mentum; median tooth very sharp, lateral lobes wide, almost truncate at apex; submentum distinctly separated from mentum, quadrisetose. Antennae sub-moniliform (Fig. 7), moderate in length for Clivinini, shorter than above species, extended to base of pronotum; antennomeres 1 and 2 glabrous and smooth, antenna pubescent from antennomere 3; antennomeres 2 and 3 subequal in length; antennomeres 5-10 somewhat flat, slightly longer than wide.

Pronotum (Fig. 9) peltate in form, much wider than head; disc smooth, moderately convex; slightly longer than wide $(\mathrm{PL} / \mathrm{PW}=1.04)$; anterior margin deeply concave, anterior angles protruded, nearly rectangular; widest at about middle; side strongly serrated just before hind angle, with three conspicuous toothed projections; marginal channel wide, ended before posterior setiferous pore; anterior setiferous pore situated at about apical fourth, posterior one at about basal third, just before hind angle, which is more obtuse than that of G. cavicola; base unbordered, almost straight; median line deep and distinct; basal transverse sulcus wide and deep, narrower than $G$. cavicola, with several transverse striae behind; anterior transverse impression free from median line, very close to anterior margin. Peduncle distinct.

Elytra wider than pronotum $(\mathrm{EW} / \mathrm{PW}=1.21)$, elongate-ovate, $\mathrm{EL} / \mathrm{EW}=1.73$; disc strongly convex; lateral margin gently expanded, widest at about middle; base more or less straight, little indentations corresponding to the intervals; shoulders with two evident serrated teeth, lateral margin distinctly crenulated throughout; striae punctate, deep, intervals strongly convex; intervals 6-8 carinate at base, base of intervals 7 and 8 separate; interval 3 with four setiferous pores, setae moderate in length for clivinines; marginal channel with uninterrupted series of small setiferous pores and several large pores with much longer setae; scutellar stria long and distinct, scutellar pore present. Hind wings reduced.

Underside of head and proepisternum with dense isodiametric punctures, without wrinkles; prosternum smooth; abdomenal sterna more or less punctured; sternum VII of female with two pairs of subapical setae; epipleuron with a few coarser punctures near base.

Legs normal for clivinines; fore leg stout, profemur moderately dilated, smooth; protibia (Fig. 11) well developed, quadridentate, with distinct and complete carina dorsally, but without sulcus; lateral upper spine elongate- ensiform, blunt at apex, much longer and stouter than subapical spur; protarsi slender, tarsomere 1 long, slightly longer than tarsomeres 2-4 combined; middle and hind legs slender, mesotibia gradually dilated towards apex, with a conspicuous tuber-like spur at subapex.

Female genitalia (Fig. 13): Lateralotergite IX weakly sclerotized, with four long setae at inner margin; gonosubcoxite IX triangular, with one long setae at median portion of outer margin; gonocoxite IX long and slender, slightly curved, apex somewhat blunt, each side of base with one long seta, and two small and short ensiform setae on outer margin.

Male: Unknown.

Remarks: This new species is similar to G. cavicola sp. nov., but it is smaller, head stouter, labrum 7-setose, palpi slightly stouter, antennae shorter and sub-moniliform, lateral margin of elytra distinctly crenulate throughout, and the female genitalia with gonocoxite IX slightly curved, and blunt at apex.

Etymology: This new species is named in honor of Dr. Anne Bedos (Muséum National d'Historie Naturelle), a well known biospeleologist.

Distribution: China (Guangxi: Longzhou Xian). The unique specimen was caught by hand beneath a piece of soil in Paoma Cave, at about $150 \mathrm{~m}$ from the entrance. The cave is as long as $4 \mathrm{~km}$, according to local villagers, but we had only explored a small part of it because of flooding (Figs. 15 and 16).

\section{ACKNOWLEDGEMENTS}

I am particularly indebted to Drs. Louis Deharveng, Thierry Deuve, and Anne Bedos (MNHN) for their encouragement during the study, especially their critical reading, correction of the text and suggestions to improve the manuscript. My thanks also to Dr. Tony Whitten (Fauna and Flora International), Ms. Liu Jin (World Bank), Mrs. Feng Bin, Li Guiyu (Biodiversity Office, Guangxi Forestry Bureau, Nanning), and Dr. Li Youbang (College of Life Sciences, Guangxi Normal University, Guilin) for their various assistances. In addition, I thank the Journal of Cave and Karst Studies Associate Editors, Advisory Board and reviewers for their encouragement and constructive criticism. This study was sponsored by the World Bank GEF-financed project Guangxi Integrated Forestry Development and Conservation.

\section{REFERENCES}

Baehr, M., 1999, Two new genera of clivinine Scaritinae from the Oriental Region (Coleoptera: Carabidae), in Zamotajlov, A., and Sciaky, R., eds., Advances in Carabidology, Krasnodar, Russia, Muiso Publishers, p. 115-126.

Balkenohl, M., 1999, New Clivinini from the Oriental region 2. Clivina rugosofemoralis nov. spec. and Rugiluclivina leonina nov. spec. from Laos (Coleoptera, Carabidae, Scaritinae): Linzer Biologische Beiträge, v. 31 , no. 1 , p. $337-344$. 
Balkenohl, M., 2001, Key and Catalogue of the Tribe Clivinini from the Oriental Realm, With Revisions of the Genera Thliboclivina Kult, and Trilophidius Jeannel (Insecta, Coleptera, Carabidae, Scarititae, Clivinini): Sofia, Pensoft Publishers, Series Faunistica no. 21, 83 p.

Barr, T.C. Jr., 1967, Antroforceps, an eyeless cave scaritine from Mexico (Coleoptera: Carabidae): The Coleopterists' Bulletin, v. 21, p. 65-70

Casale, A., and Marcia, P., 2011, Two new Typhloreicheia species from Sardinia and their biogeographical significance (Coleoptera, Carabidae, Scaritinae): ZooKeys, v. 134, p. 15-31. doi:10.3897/zookeys.134.1707.

Casale, A., Vigna Taglianti, A., and Juberthie, C., 1998, Coleoptera Carabidae, in Juberthie, C., and Decu, V., eds., Encyclopaedia Biospeologica vol. II, Moulis and Bucarest, Société Internationale de Biospéologie, p. 1047-1081.

Chen Zhiping, Decu, V., Juberthie, C., and Uéno, S.-I., 2001, Chine, in Juberthie, C., and Decu, V., eds., Encyclopaedia Biospeologica vol. III, Moulis and Bucarest, Société Internationale de Biospéologie, p. $1763-1781$.

Decu, V., Nitzu, E., and Juberthie, C., 1994, Clivina subterranea (Caraboidea, Scaritidae), nouvelle espèce de la grotte "Peştera de la Movile", Dobrogea Méridionale, Roumanie: Mémoires de Biospéologie, v. 21, p. $41-45$.

Deuve, T., 1993, L'Abdomen et les Genitalia des Femelles de Coléoptères Adephaga: Mémoires du Muséum National d'Histoire Naturelle, no. $155,184 \mathrm{p}$.

Deuve, T., 2001, Deux nouveaux Semiaphaenops de Chine, cavernicoles dans un karst du nord-est Yunnan (Coleoptera, Trechidae): Nouvelle Revue d'Entomologie, v. 18, p. 187-192.

Deuve, T., 2003, Un Clivinini troglobie anophtalme d'un karst de NouvelleBretagne, en Papouasie-Nouvelle Guinée (Coleoptera: Caraboidea: Scaritidae): Nouvelle Revue d'Entomologie, v. 20, p. 231-235.

Deuve, T., 2004, Deux nouvelles Jujiroa cavernicoles de sud de la Chine et du nord du Vietnam (Coleoptera, Caraboidea): Bulletin de la Societe entomologique de France, v. 109, p. 361-366.
Jeannel, R., 1957, Révision des petits Scaritides endogés voisin de Reicheia Saulcy: Revue Française d'Entomologie, v. 24, p. 129-212.

Miller, L., 1863, Ein neuer Grottenkäfer aus der Gruppe der Scaritiden: Wiener entomologische Monatsschrift, v. 7, p. 28-30.

Müller, G., 1938, Italodytes stammeri, nuove genere e nuova specie di carabidi cavernicoli dell'Italia meridionale: Atti del Museo Civico di Storia Naturale di Trieste, v. 13, p. 135-139.

Putzeys, J., 1866, Révision générale des Clivinides: Annales de la Société Entomologique de Belgique, Bruxelles, v. 10, 242 p.

Tian Mingyi, 2008, An overview to cave-dwelling carabid (Insecta: Coleoptera) in China: Proceedings of the 14th National Conference of Speleology, Wulong, Chongqing (in Chinese), p. 333-342.

Tian Mingyi, 2009, New records and new species of cave-dwelling trechine beetles from Mulun Nature Reserve, northern Guangxi, China (Insecta: Coleoptera: Carabidae: Trechinae): Subterranean Biology, v. 7, p. 69-73.

Uéno, S.-I., 2007, Occurrence of a New Cave Species of Jujiroa (Coleoptera, Carabidae, Platyninae) from Central Sichuan, Southwest China: Elytra, v. 35, no. 1, p. 21-26.

Uéno, S.-I., and Kishimoto, T., 2001, A new cave species of the genus Jujiroa (Coleoptera, Carabidae, Platyninae) from southern Sichuan, Southwest China: Journal of Speleological Society of Japan, v. 26, p. $30-36$.

Uéno, S.-I., and F.X. Wang, 1991, Discovery of a highly specialized cave trechine (Carabidae: Trechinae) in Southwest China: Elytra, v. 19, p. $127-135$.

Vigna Taglianti, A., 1995, A new Jujiroa from Sichuan, China (Coleoptera, Carabidae): International Journal of Speleology, v. 23, no. 3-4, p. 179-189.

Yang Defang, and Tian Mingyi, 2008, Two new record genera of Clivinini in China (Coleoptera: Carabidae): Entomotaxonomia, v. 30, no. 4, p. $255-258$. 